\title{
Nickel Phosphide Electroless Coating on Cellulose Paper for Lithium Battery Anode
}

\author{
Hyeong-Ku Kang and Heon-Cheol Shin* \\ School of Materials Science and Engineering, Pusan National University, Busandaehak-ro 63 beon-gil, Geumjeong-gu, \\ Busan 46241, South Korea
}

\begin{abstract}
Here we report our preliminary results about nickel phosphide (Ni-P) electroless coating on the surface of cellulose paper (CP) and its feasibility as the anode for lithium (Li) batteries. In particular, CP can act as a flexible skeleton to maintain the mechanical structure, and the Ni-P film can play the roles of both the anode substrate and the active material in Li batteries. Ni-P films with different P contents were plated uniformly and compactly on the microfiber strands of CP. When they were tested as the anode for Li battery, their theoretical capacity per physical area was comparable to or higher than hypothetical pure graphite and P film electrodes having the same thickness. After the large irreversible capacity loss in the first charge/discharge process, the samples showed relatively reversible charge/discharge characteristics. All samples showed no separation of the plating layer and no detectable micro-cracks after cycling. When the charge cut-off voltage was adjusted, their capacity retention could be improved significantly. The electrochemical result was just about the same before and after mechanical bending with respect to the overall shape of voltage curve and capacity.
\end{abstract}

Keywords : Cellulose paper; Fiber; Electroless Coating, Nickel Phosphide, Lithium Battery

Received : 19 November 2019, Accepted : 15 December 2019

\section{Introduction}

The fourth industrial revolution has led to the emergence of hyper connectivity, superintelligence, automation, and mobility. Consequently, light-weight flexible batteries are gaining popularity for operating portable, wearable electronic devices. The development of flexible substrates and electrode materials is the most important step in the realization of a flexible energy-storage device [1]. Metals that have been conventionally used for the substrate are susceptible to mechanical deformations such as bending, twisting, and stretching, which limits their use in flexible energy-storage devices. To address this issue, studies have been conducted on polymer [2], paper [3], or textile [4] coated with a conductive material for use as a substrate.

In particular, paper is fairly inexpensive, environ-

*E-mail address: hcshin@pusan.ac.kr

DOI: https://doi.org/10.33961/jecst.2019.00654

This is an open-access article distributed under the terms of the Creative Commons Attribution Non-Commercial License (http://creativecommons.org/licenses/by-nc/4.0) which permits unrestricted non-commercial use, distribution, and reproduction in any medium, provided the original work is properly cited. ment friendly, light weight, and flexible, thereby making it suitable for use in flexible electrodes [5]. Because it has a wide surface area, excellent battery characteristics can be expected by evenly coating its surface with a conductive material; the use of silver nanowire films [6], conductive polymers [7], metals, and carbon-based materials (e.g., carbon nanotubes [8], graphene [9], etc.) as the conductive coating has been investigated. Layer-by-layer ( $\mathrm{LbL}$ ) assembly [10], dip coating [11], dry coating [12], electro- and electroless plating $[13,14]$ are among the known coating methods. Through electroless plating, microfiber strands can be coated with a uniform thickness and at a low cost; various metals such as nickel, copper, gold, platinum, and cobalt can also be used as the conductive coating via electroless plating [15].

Nickel phosphide has a wide variety of applications for functional electrochemical devices [16-18]. In particular, much work has been recently made on its use for the anode in rechargeable lithium (Li) battery owing to its high theoretical specific capacity $[19,20]$. As far as we know, however, there was no report about metal phosphide coating on flexible sub- 
strate like paper, fiber, and polymer for the use of $\mathrm{Li}$ battery anode. Only a few works dealt with the electrochemical or electroless coating of metal phosphide anode on nearly inflexible foam frameworks [21,22].

In this study, a metal alloy was coated on the surface of cellulose paper (CP) to test its feasibility as the anode for Li batteries. Specifically, Hanji, Korean traditional paper, features excellent durability and mechanical strength, and the fiber bonding of Hanji is stronger than that of western paper [23]; via electroless plating, its surface was coated with inexpensive nickel phosphide (Ni-P) with low surface resistance (below $0.5 \Omega \square^{-1}[24,25]$ ). Unlike conventional methods that utilize two separate materials for the flexible substrate and electrodes, $\mathrm{CP}$ can act as a flexible skeleton to maintain the mechanical structure, and the Ni-P film coated via electroless plating can play the roles of both the anode substrate and the active material (electrode material) in Li batteries.

First, electroless-plating conditions were varied to form films with different Ni-to-phosphorus (P) ratios on the surface of CP. The crystal structure and morphology (uniformity) of the formed films were analyzed, and the maintenance of structural integrity during the bending process was checked. To test the applicability of the CP/Ni-P film samples as Li battery anode, the charge/discharge capacity, lifespan, and resistance properties of the anode were analyzed. Moreover, the charge/discharge tendencies of the electrode before and after the mechanical bending were compared to identify the stress-induced changes in the electrochemical properties.

\section{Experimental}

\subsection{Preparation of Ni-P electroless coating on CP}

Hanji $(100 \mu \mathrm{m}$ in thickness, $20 \mu \mathrm{m}$ in fiber diameter) was used for a flexible substrate. Electroless coating of Ni-P film on CP basically consists of pretreatments (i.e., sensitizing and activation) and main process (i.e., electroless deposition). Sensitizing process was done for $20 \mathrm{~min}$. in an aqueous solution of
$0.026 \mathrm{M}$ tin chloride (Alfa Aesar, 98\%), while activation process was carried out for $30 \mathrm{~min}$. in a mixed aqueous solution of $1.7 \mathrm{mM}$ palladium chloride (Aldrich, 99\%) and $0.32 \mathrm{M}$ boric acid (Junsei, 99.5\%). The $\mathrm{pH}$ was set to 1 and 2 with hydrochloric acid (Junsei, 35\%) in sensitizing and activation process, respectively.

Main deposition process was performed at $45^{\circ} \mathrm{C}$. The deposition bath includes $0.097 \mathrm{M}$ nickel sulfate (Junsei, 98.0\%), 0.027 M trisodium citrate dehydrate (Junsei, 99\%), $0.34 \mathrm{M}$ ammonium chloride (Junsei, 98.5\%), and $0.04 \sim 0.5 \mathrm{M}$ sodium hypophosphite (Sigma-aldrich, 99\%). The $\mathrm{pH}$ was controlled from 6 to 11 by sodium hydroxide (Junsei, $97.0 \%$ ). Three compositions of deposition bath for electroless coating were given in Table 1. The solution was stirred with a magnetic stirrer during all the processes. The prepared samples were washed in distilled water and air-dried. Some samples were treated with dilute hydrochloric acid to remove the native oxide layer on the films.

The surface and cross-sectional morphology, composition, and crystal structure of the films were analyzed using field-emission scanning electron microscope (FE-SEM, MIRA3, TESCAN, Czech Republic), energy dispersive X-ray spectrometer (EDS, 51-XMX1004, Oxford instruments, UK), Xray diffractometer (XRD, Ultima-IV Rigaku, Japan), respectively.

\subsection{Electrochemical Tests}

For the tests of $\mathrm{CP} / \mathrm{Ni}-\mathrm{P}$ samples as the anode in $\mathrm{Li}$ batteries, three-electrode beaker cell was constructed in a glove box (Mbraun-Unilab, Germany) with high purity $\operatorname{Ar}$ gas $\left(\mathrm{O}_{2}, \mathrm{H}_{2} \mathrm{O}<1 \mathrm{ppm}\right)$. Li foil was used as the counter and reference electrode. The electrolyte was a $1 \mathrm{M}$ solution of lithium hexafluorophosphate in a 3:7 volume mixture of ethylene carbonate and ethyl methyl carbonate.

In order to explore the effect of $\mathrm{P}$ content in Ni-P film on the specific capacity and cycling stability, the charge/discharge experiments were performed for

Table 1. Electroless plating conditions used in the present study

\begin{tabular}{ccccc}
\hline \hline Number & Concentration of sodium hypophosphite $(\mathrm{M})$ & $\mathrm{pH}$ & Deposition time $(\mathrm{min})$ & Deposition temperature $\left({ }^{\circ} \mathrm{C}\right)$ \\
\hline 1 & 0.04 & 11 & 20 & 45 \\
2 & 0.14 & 8 & 20 & 45 \\
3 & 0.5 & 6 & 20 & 45 \\
\hline
\end{tabular}


three samples with different $\mathrm{P}$ contents. The cells were galvanostatically charged at a rate of $1 \mathrm{mAcm}^{-2}$ to $0.01,0.1$, or $0.3 \mathrm{~V}$ vs. $\mathrm{Li} / \mathrm{Li}^{+}$, followed by a constant potential charging until the current has decreased to $0.2 \mathrm{mAcm}^{-2}$. They were subsequently discharged at a rate of $1 \mathrm{~mA} / \mathrm{cm}^{2}$ to $3 \mathrm{~V}$ vs. $\mathrm{Li} / \mathrm{Li}^{+}$. The above charge/discharge cycle was repeated 20 times. To estimate the interfacial resistance during charge/discharge cycle, electrochemical impedance spectroscopy (EIS) measurements were conducted over the frequency range of $10 \mathrm{kHz}$ to $0.1 \mathrm{mHz}$ at a potential fluctuation of $5 \mathrm{mV}(\mathrm{rms})$. Some $\mathrm{CP} / \mathrm{Ni}-\mathrm{P}$ film samples were bent by wrapping them around a cylinder having a diameter of $3 \mathrm{~mm}$, and their charge/ discharge characteristics were analyzed. A VMP3 system (BioLogic Co., Claix, France) was used for all the electrochemical measurements.

\section{Results and Discussion}

To obtain Ni-P films with different $\mathrm{P}$ contents via electroless plating, the concentration of sodium hypophosphite (used as the reducing agent) and the $\mathrm{pH}$ (i.e., the concentration of sodium hydroxide) were adjusted (Table 1). Because the reducing agent acts as the $\mathrm{P}$ source, increasing its concentration is expected to increase the $\mathrm{P}$ content, and this tendency has already been reported in a previous study [26]. Further, considering the electroless-plating reaction mechanism presented below [27], it is evident that the $\mathrm{pH}$ also influences the $\mathrm{P}$ content.

$$
\begin{aligned}
& \quad\left(\mathrm{NiR}_{\mathrm{n}}\right)^{2+}+\mathrm{H}_{2} \mathrm{PO}_{2}{ }^{-}+3 \mathrm{OH}^{-} \\
& \quad \rightarrow \mathrm{Ni}+\mathrm{HPO}_{3}{ }^{2-}+2 \mathrm{H}_{2} \mathrm{O}+\mathrm{nR} \\
& \mathrm{H}_{2} \mathrm{PO}_{2}^{-}+2 \mathrm{H}^{+}+\mathrm{e} \rightarrow \mathrm{P}+2 \mathrm{H}_{2} \mathrm{O}
\end{aligned}
$$

Specifically, an increase in the $\mathrm{pH}$ (i.e., an increase in the hydroxide ions in the solution) facilitates reaction (1) and inhibits reaction (2), thereby yielding a relatively low $\mathrm{P}$ content in the layer plated via electroless plating. Consequently, the $\mathrm{P}$ content in the layer tends to be proportional to the concentration of the reducing agent and inversely proportional to the $\mathrm{pH}$. Therefore, increasing the concentration of the reducing agent and lowering the $\mathrm{pH}$ is ideal for obtaining a high $\mathrm{P}$ content, whereas the opposite is ideal for obtaining a low $\mathrm{P}$ content. The conditions presented in Table 1 have been derived as a result of repeated experiments on this basis.
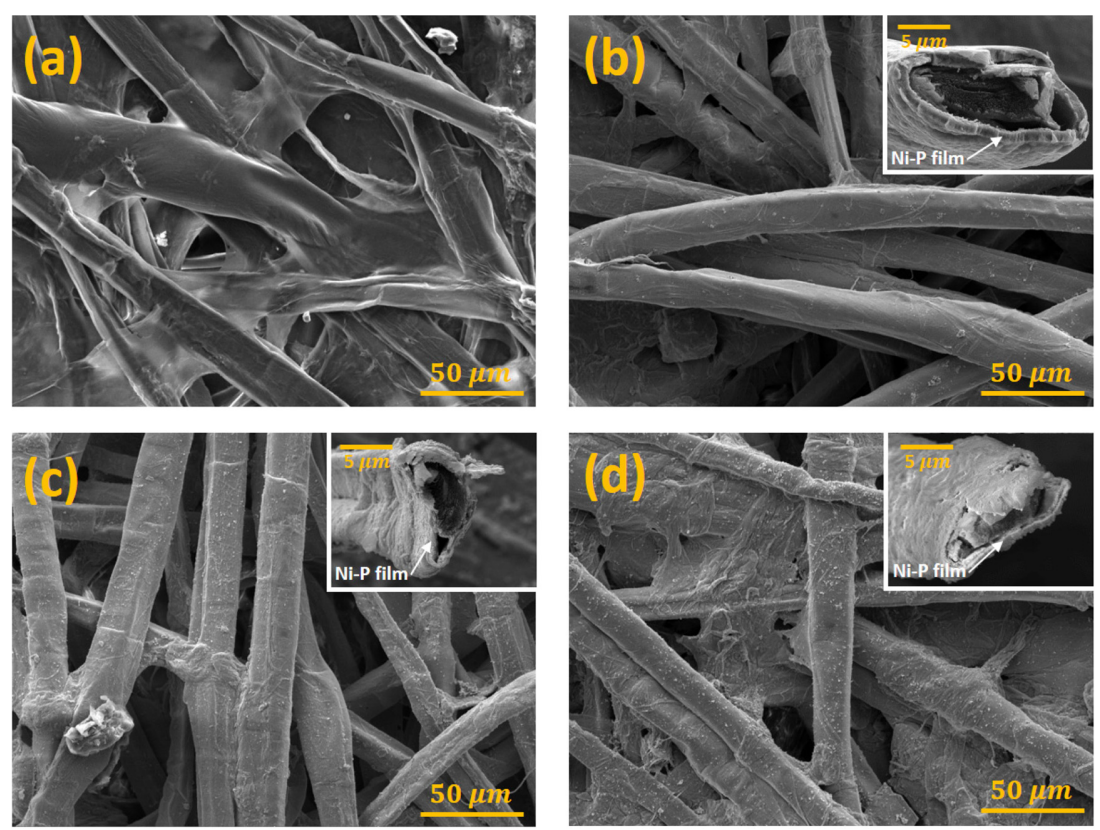

Fig. 1. (a) Electron-microscopy image of the CP before electroless plating. (b), (c), and (d) are the images of the CP/Ni-P film samples fabricated under the conditions 1, 2, and 3 presented in Table 1, respectively. 
Fig. 1 represents the electron-microscopy images of the $\mathrm{CP}$ before electroless plating and the $\mathrm{CP} / \mathrm{Ni}-\mathrm{P}$ film samples fabricated under three different electroless-plating conditions presented in Table 1. Before electroless plating, the $\mathrm{CP}$ had crosslinked microfiber strands with a diameter of approximately $20 \mu \mathrm{m}$ (Fig. $1(\mathrm{a})$ ), and as a result, it had a very large surface area, and many pores were present inside it. Therefore, when a thin layer of the substrate/active material is uniformly coated on the fiber strands that comprise the $\mathrm{CP}$, high capacity and low reaction resistance per physical area can be expected. Moreover, electrolyte impregnation becomes easier owing to the presence of numerous pores between the fiber strands. Figs. 1(b), (c), and (d) represent the electron-microscopy images obtained after Ni-P film is coated on the surface of $\mathrm{CP}$ via electroless plating under conditions 1 , 2 , and 3 , respectively. In all the three cases, Ni-P was plated uniformly on the microfiber strands. The inset image suggests that the thickness of the Ni-P layer was approximately $1 \mu \mathrm{m}$, highlighting the high-density plating.

Fig. 2 presents the results of the component analysis performed via EDS. Carbon and oxygen, which are the main components of cellulose, were mostly detected in the CP (Fig. 2(a)), whereas the P content in the layers coated via electroless plating under conditions 1,2 , and 3 was $\sim 3$ at $\%$ (hereafter referred to as NiP3), $\sim 6$ at $\%$ (hereafter referred to as NiP6), and $\sim 10$ at $\%$ (hereafter referred to as NiP10), respectively (Figs. 2(b), (c) and (d)). In the analysis of the crystal structure of the plated layer (Fig. 3), all three samples contained severe noise with diffraction signals. Although it appeared that the sample NiP3 has a partial crystallinity of $\mathrm{Ni}$ and/or Ni-P alloy, the corresponding signals were very weak and broad, and
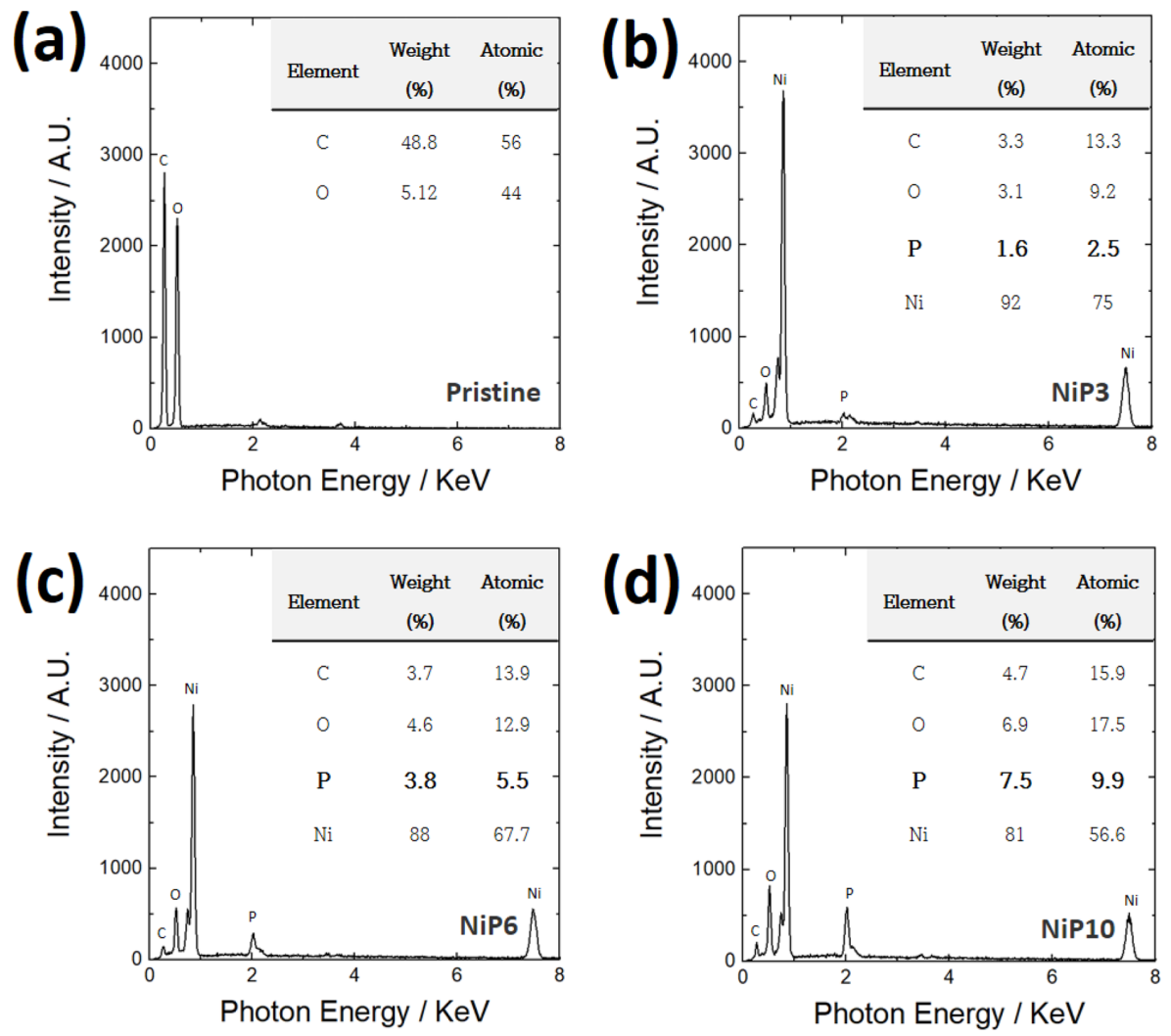

Fig. 2. (a) EDS spectrum of the CP before electroless plating. (b), (c), and (d) are the spectra of the CP/Ni-P film samples fabricated under the conditions 1,2 , and 3 presented in Table 1 , respectively. 


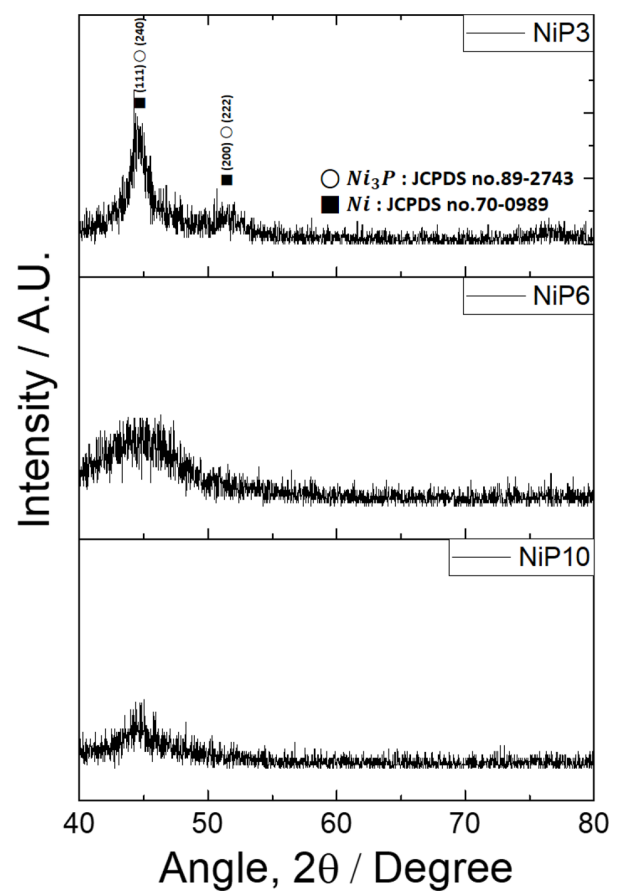

Fig. 3. X-ray diffraction patterns of the samples.

those from $\mathrm{Ni}$ and Ni-P alloy were hardly differentiable. Such signals obtained from NiP6 and NiP10 were observed far less clearly. These results reveal the short-range order in the structures of $\mathrm{Ni}$ and $\mathrm{Ni}-\mathrm{P}$ alloy. It has been reported that the crystal structure of $\mathrm{Ni}-\mathrm{P}$ coated via electroless plating is associated with the $\mathrm{P}$ content. When the $\mathrm{P}$ content is low $(2 \mathrm{wt} \%)$, it has crystalline properties, but as the $\mathrm{P}$ content increases, it becomes more amorphous; when the P content exceeds $10 \mathrm{wt} \%$, it becomes completely amorphous [28]. In this study, distinct X-ray diffraction signals were hardly observed even when the $\mathrm{P}$ content was relatively low; this can be attributed to the significantly low amount of crystalline materials.

For measuring the adhesive strength of the plated layers, scratch [29] and splat adhesion tests [30] are typically used. However, because the samples fabricated in this study had the constraint of having a film layer formed on microfiber, it was difficult to obtain meaningful results using the conventional adhesivestrength tests. Instead, this study attempted to indirectly confirm the adhesive strength by observing whether the Ni-P film coated on the microfiber maintained its structural integrity when the fabricated

\section{(a)}
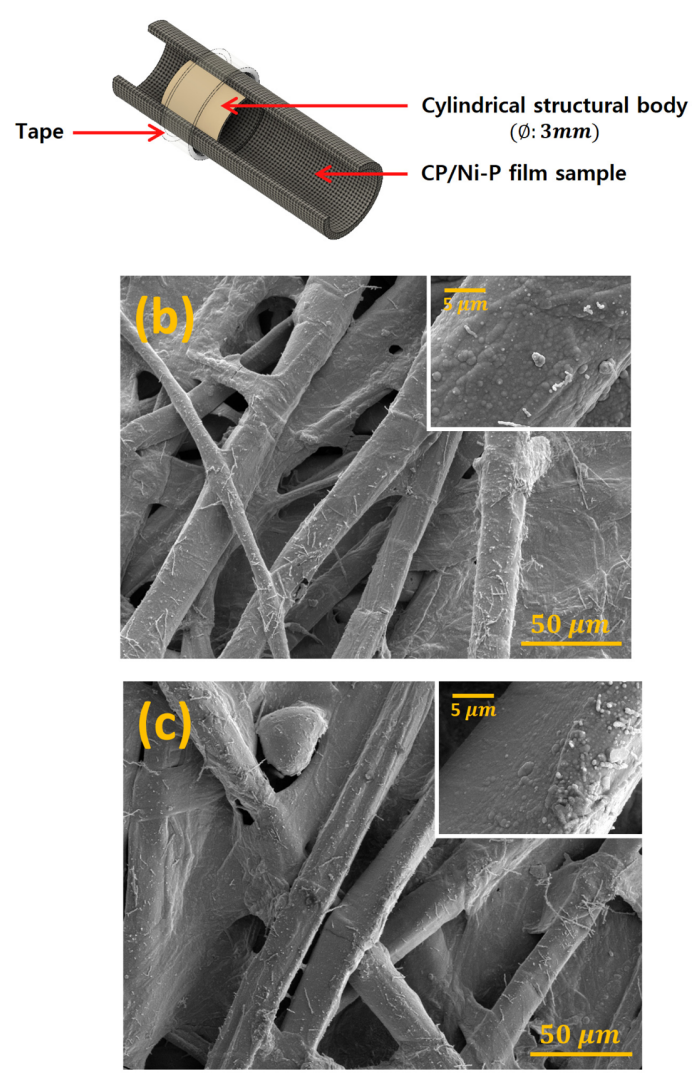

Fig. 4. (a) Schematic representation of bending test of $\mathrm{CP} /$ Ni-P film sample. Electron microscopy images of (b) the inner and (c) outer parts of the coated layer after bending.

samples were bent. As shown in Fig. 4(a), the bending test was performed by wrapping a cylindrical structural body with a diameter of $3 \mathrm{~mm}$ with the $\mathrm{CP} /$ Ni-P film samples. To check for damages caused to the film after bending, it was separated from the structural body, and the morphology of the part of the plated layer that was bent was observed with an electron microscope. Compressive and tensile stresses acted on the inner (Fig. 4(b)) and outer (Fig. 4(c)) parts of the coated layer, respectively; the parts did not separate, and no micro-cracks of any kind were observed via electron microscopy.

The CP/Ni-P film samples fabricated above were tested as anode active material for Li battery. Typically, when an active material is coated on a metal substrate, an increase in the thickness of the active 
material results in an increased capacity, and it also increases the electron migration distance that, in turn, leads to overvoltage, thereby causing a negative impact on the rate properties. Additionally, the contact resistance between the substrate and active material can hinder high-rate operation. However, in the electrode fabricated in this study, there was no actual contact resistance between the substrate $(\mathrm{Ni})$ and active material (Ni-P) because they exist in a single form and exhibit excellent electron mobility. Thus, from a materials engineering perspective, the fabricated Ni-P film assembly can be considered an ideal form of an electrode.

Because the amount of $\mathrm{P}$, the active element in the fabricated Ni-P film, was not large, it is difficult to expect a significant effect on the capacity per weight. In other words, when rough calculations were made based on the results of weight and component analysis (Fig. 2) under the assumption that all $\mathrm{P}$ present in $\mathrm{Ni}-\mathrm{P}$ film reacted with $\mathrm{Li}$; NiP3, NiP6, and NiP10 were estimated to have a specific theoretical capacity of $42 \mathrm{mAhg}^{-1}, 99 \mathrm{mAhg}^{-1}$, and $195 \mathrm{mAhg}^{-1}$, respectively. These results showed that even the specific capacity with the highest P content (NiP10) did not reach the level of graphite $\left(372 \mathrm{mAhg}^{-1}\right)$. However, the situation is different when considering the capacity per physical area $\left(\mathrm{mAhcm}^{-2}\right)$, which is one of the key indicators in film electrodes. As shown in Table 2 , the theoretical capacity per physical area of all samples fabricated in the present study was much higher than hypothetical pure graphite film $\left(84 \mathrm{mAhcm}^{-2}=372 \mathrm{mAhg}^{-1} \times 2.27 \mathrm{gcm}^{-2}\right.$ (density) $\times$ $1 \mathrm{~mm}$ (thickness)) having the same thickness. As compared to that of hypothetical pure $\mathrm{P}$ film $\left(472 \mathrm{mAhcm}^{-2}=2596 \mathrm{mAhg}^{-1} \times 1.82 \mathrm{gcm}^{-2}\right.$ (density) $\times 1 \mathrm{~mm}$ (thickness)), the theoretical areal capacity of our samples is almost equal (NiP3) or higher (NiP6 and NiP10). It is noteworthy that the thickness of the $\mathrm{CP}$ adopted in this work is only $100 \mu \mathrm{m}$. One can easily increase the areal capacity of $\mathrm{CP} / \mathrm{Ni}-\mathrm{P}$ film by selecting thicker $\mathrm{CP}$ having more fiber strands. The above results imply that the fiber/Ni-P film fabricated in this study can be a promising option for a power source of wearable electronic devices, for which the capacity per physical area is an important factor.

Fig. 5 shows the charge/discharge curves for the first three cycles of three different samples with varying P content. Large irreversible capacity loss

Table 2. Theoretical capacity per gram and physical area of the samples fabricated in the present work

\begin{tabular}{|c|c|c|c|c|}
\hline \multirow{2}{*}{ Number } & \multirow{2}{*}{ Deposit weight (mg) } & \multirow{2}{*}{$\mathrm{P}$ content (at \%) } & \multicolumn{2}{|c|}{ Theoretical (Calculated) capacity } \\
\hline & & & Gravimetric $\left(\mathrm{mAhg}^{-1}\right)$ & Areal $\left(\mathrm{mAhcm}^{-2}\right)$ \\
\hline $1(\mathrm{NiP} 3)$ & 10 & 2.5 & 42 & 415 \\
\hline 2 (NiP6) & 9 & 5.5 & 99 & 888 \\
\hline 3 (NiP10) & 4 & 9.9 & 195 & 779 \\
\hline
\end{tabular}

(a)

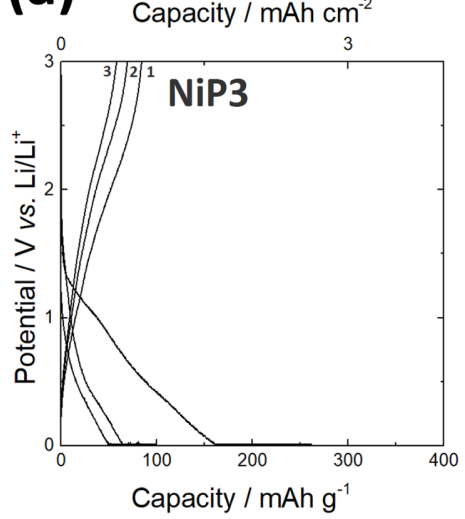

(b)

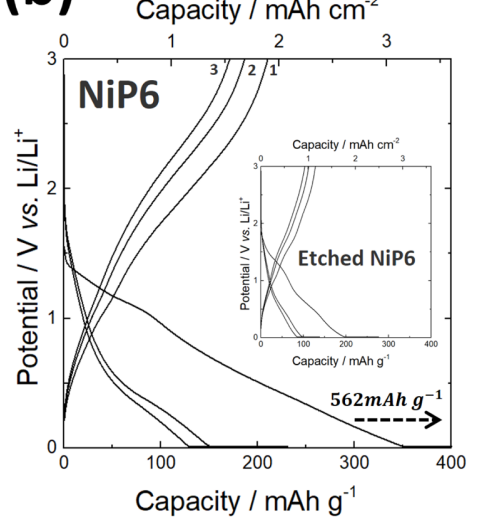

(c)

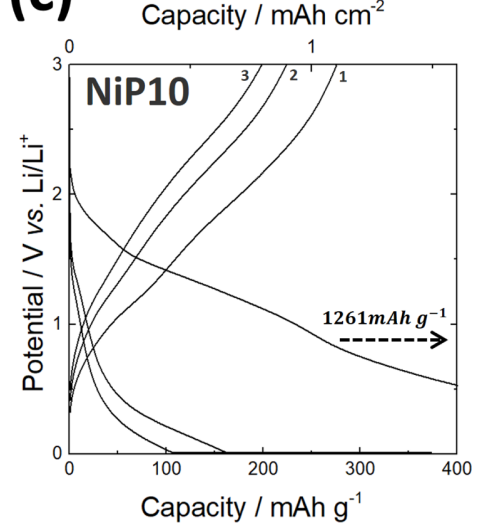

Fig. 5. Charge/discharge curves for the first three cycles of (a) NiP3, (b) NiP6, and (c) NiP10. 
was seen in the first charge/discharge process, similar to the previous works on the anode that reacts with $\mathrm{Li}$ according to a conversion mechanism [31-34]. It is generally believed that such an initial capacity loss is mainly caused by the decomposition of electrolyte, forming a solid electrolyte interphase (SEI) on the electrode surface, and partially attributed to the irreversible insertion of Li ions into the Ni-P [35].

Notably, all the samples were reversibly charged/ discharged in the subsequent processes. It should be mentioned that the areal discharge capacity values of all three samples were higher than the theoretical capacity presented in Table 2 . This higher value might be attributed to the presence of $\mathrm{NiO}$ on the film surface and this possibly provides additional capacity by the reaction between $\mathrm{NiO}$ and $\mathrm{Li}$ [36]. In order to confirm the above arguments, the charge/discharge experiment was conducted on samples with $\mathrm{NiO}$ removed from the surface by chemical etching. The result showed a dramatic decrease in reversible discharge capacity close to the theoretical one (inset in the image of Fig. 5(b)). Fig. 6 shows the capacity retention of three samples during 20 cycles of charge/ discharge. As P content decreased, the capacity retention increased. Nevertheless, even in the case of the sample with the lowest P content (NiP3), the capacity retention was not so satisfactory.

Active materials, such as Ni-P, which undergo reaction by conversion mechanism, tend to show structural failure due to volumetric change during alloying/dealloying with Li [37]. To analyze whether such structural failure could be a cause of the decline in lifespan properties, changes in structural integrity and morphology of Ni-P film were analyzed after the cycling test. As shown in Fig. 7(a), NiP3 with relatively low $\mathrm{P}$ content showed almost no change in surface morphology after cycling. However, as the $\mathrm{P}$

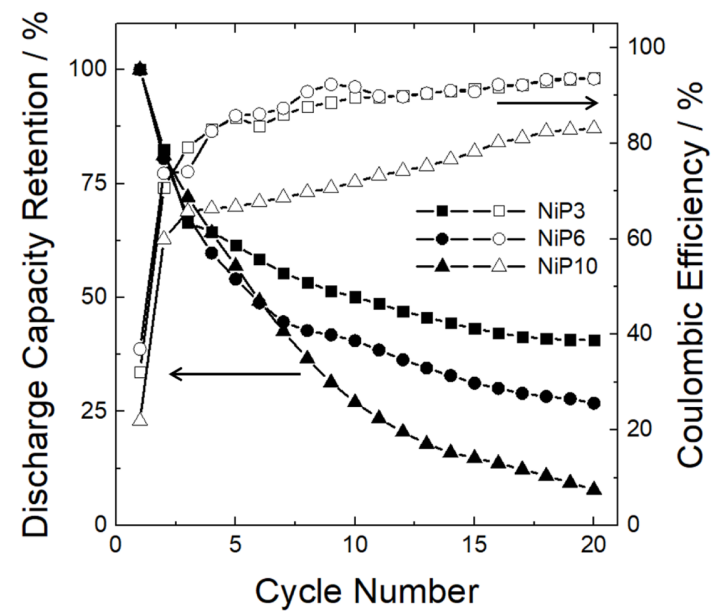

Fig. 6. Discharge capacity retention and coulombic efficiency during 20 cycles.

content increased (NiP6 and NiP10), the surface became very rough after charge/discharge (Figs. 7(b),(c)). It is believed that this is due to the relatively large amount of $\mathrm{P}$ reacting repeatedly with $\mathrm{Li}$ and thus severe local expanding and shrinking of the film. Besides, the SEI growth on the surface became more severe. Despite such changes in surface morphology, all three samples showed no separation of the plating layer, and no detectable micro-cracks were found in electron microscopy. Fig. 8 shows the changes in impedance with the increasing number of cycles. After 20 cycles of charge/discharge, interfacial resistance (arc size on Nyquist plot) increased by approximately 3-fold. As mentioned above, if physical changes during charge/discharge, such as separation of the film layer or micro-cracks are minimal, then an increase in the interfacial resistance may be attributed to excessive growth of the SEI layer.
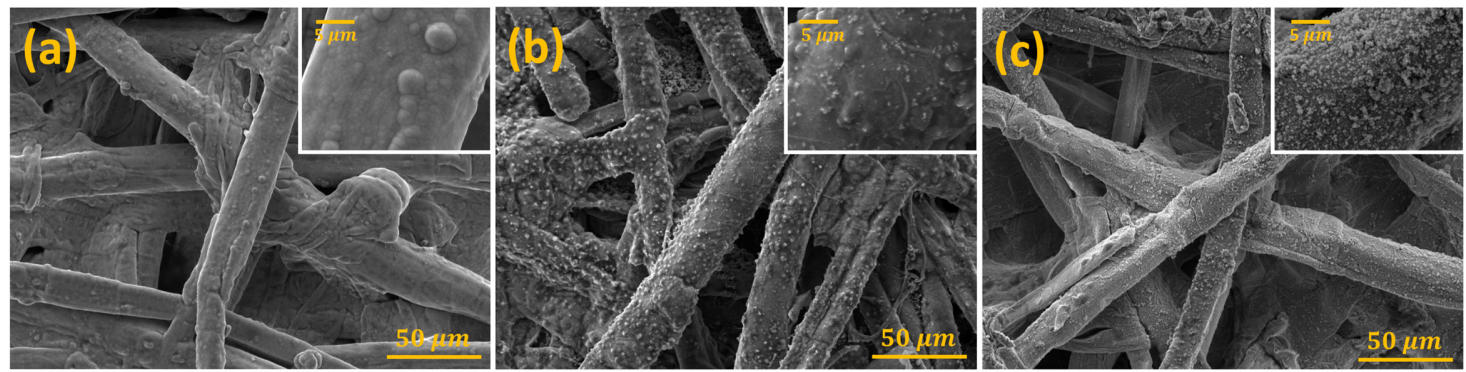

Fig. 7. Electron-microscopy images after cycling test. (a) NiP3, (b) NiP6, and (c) NiP10. 


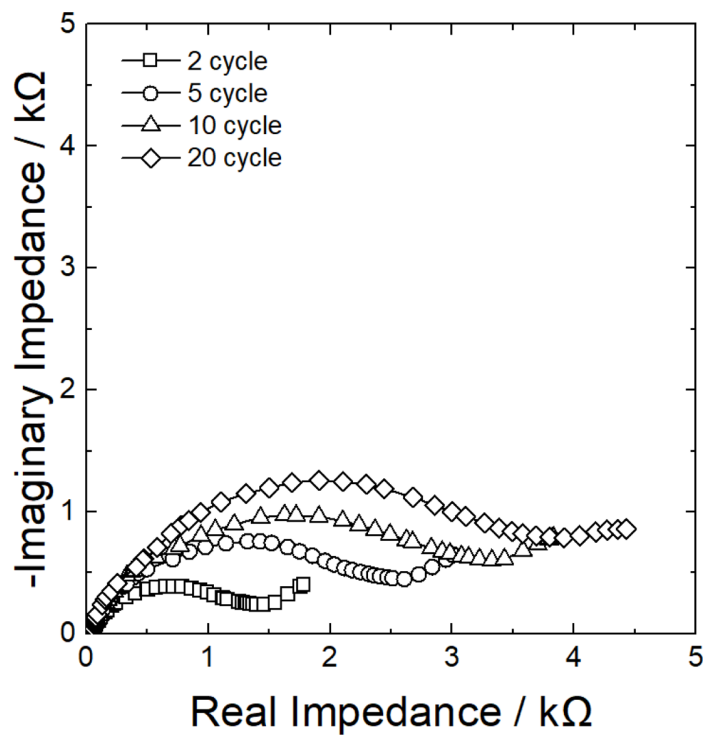

Fig. 8. Nyquist plots of NiP6 during the charge/discharge cycles.

To improve the lifespan properties under such a situation, the capacity retention rate was observed while increasing the charge cut-off voltage (lowerlimit voltage) from $0.01 \mathrm{~V}$ vs. $\mathrm{Li} / \mathrm{Li}^{+}$to 0.1 and $0.3 \mathrm{~V}$ vs. $\mathrm{Li} / \mathrm{Li}^{+}$. In other words, since most of the SEI formation reaction is believed to occur below $0.8 \mathrm{~V}$ vs. $\mathrm{Li} / \mathrm{Li}^{+}$[38], increasing lower-limit voltage could reduce undesirable growth of the SEI layer. Figs. 9(a1),(a-2) show the typical charge/discharge curves of NiP3 for the first three cycles when charge cut-off voltage was adjusted. Fig. 9(b) shows the capacity retention during 20 cycles of the charge/discharge under corresponding charge conditions. As the cutoff voltage was increased, the capacity retention rate increased significantly. Although the cycling performance needs to be further improved from the practical viewpoint, it is noted that the discharge capacity per physical area at the 20 th cycle maintained to be comparable to the capacity of hypothetical pure $\mathrm{P}$ film electrode having the same thickness (presented in figure), in spite of the reduced operating voltage range.

Lastly, the bending test was performed to determine the applicability as a power source for wearable devices. The $\mathrm{CP} / \mathrm{Ni}-\mathrm{P}$ film samples were bent by wrapping them around a cylinder having a diameter of $3 \mathrm{~mm}$. When the charge/discharge experiment was $(a-1)$

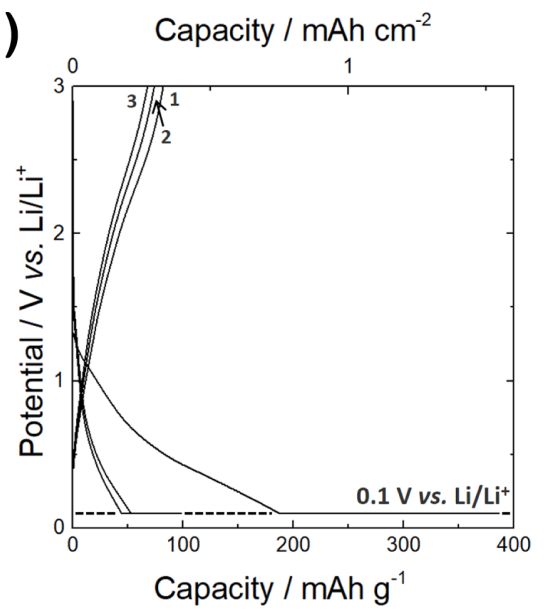

$(\mathbf{a}-2)$

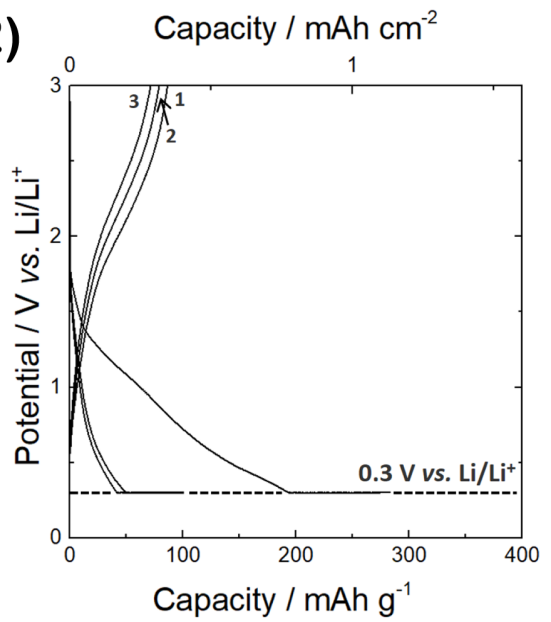

(b)

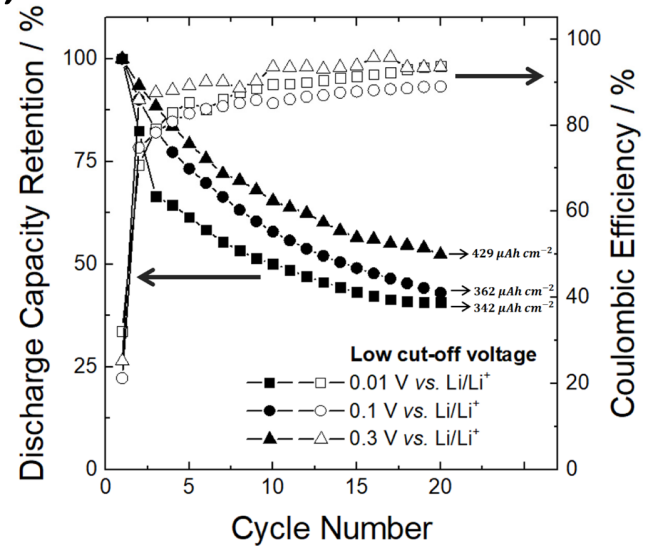

Fig. 9. Charge/discharge curves for the first three cycles of NiP3 with different low cut-off voltages of (a-1) 0.1 and (a-2) $0.3 \mathrm{~V}$ vs. $\mathrm{Li} / \mathrm{Li}^{+}$. (b) is the discharge capacity retention and coulombic efficiency during 20 cycles. 
(a)

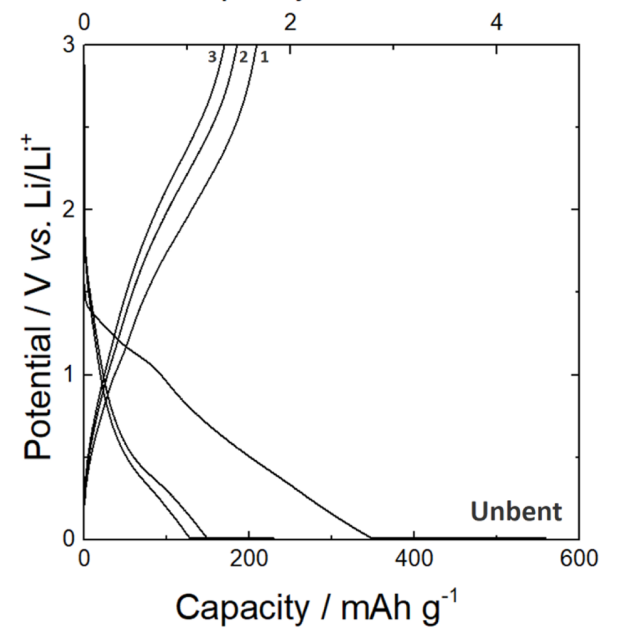

(b) Capacity / $\mathrm{mAh} \mathrm{cm}^{-2}$

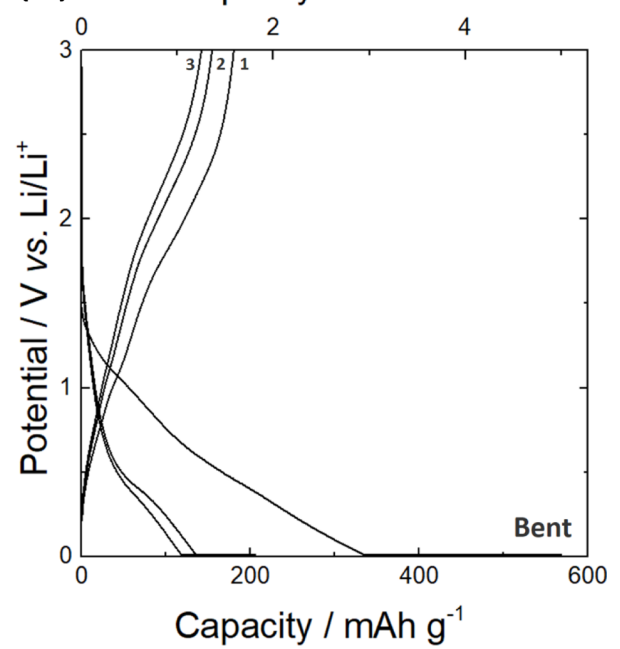

Fig. 10. Charge/discharge curves for the first three cycles of NiP6 (a) before and (b) after bending.

conducted on the bent samples, the results were just about the same before and after bending with respect to the overall shape of voltage curve and capacity (Fig. 10).

\section{Conclusions}

In this study, the preliminary results on the nickel phosphide (Ni-P) films coated via electroless plating on the surface of cellulose paper (CP) and their feasibility as the lithium (Li) battery anode were reported.
The results are summarized as follows:

1. The Ni-P films were coated uniformly and compactly via electroless plating on the microfiber strands of $\mathrm{CP}$. The $\mathrm{P}$ content in the layer was proportional to the concentration of the reducing agent and inversely proportional to the $\mathrm{pH}$. There were no longrange order in structure of all samples. The films did not separate, and no micro-cracks of any kind were observed after mechanical bending.

2. The fabricated CP/Ni-P assembly was tested as the anode for Li battery. Especially, CP can act as a flexible skeleton to maintain the mechanical structure, and the Ni-P film can play the roles of both the anode substrate and the active material. After the large irreversible capacity loss in the first charge/discharge process, the samples were cycled reversibly. The samples showed no film separation and no detectable micro-cracks after the repeated charge/discharge cycles. The electrochemical properties were just about the same before and after bending.

3. The theoretical capacity per physical area of the samples fabricated in this work was comparable to or higher than hypothetical pure graphite and P film electrodes having the same thickness. This implies that the $\mathrm{CP} / \mathrm{Ni}-\mathrm{P}$ films might be a promising option for a power source of wearable electronic devices where the capacity per physical area is an important factor.

4. From the analyses of surface morphology and interfacial resistance, it was suggested that the growth of solid electrolyte interphase could be responsible for low capacity retention of the samples. Although the capacity retention could be enhanced by increasing the charge cut-off voltage (lower-limit voltage), it needs to be further improved for practical applications.

\section{Acknowledgement}

This work was supported by the National Research Foundation (NRF-2017R1D1A3B04031667, 2018R1A5A1025594) of the Ministry of Science and ICT.

\section{References}

[1] X. Wang, X. Lu, B. Liu, D. Chen, Y. Tong and G. Shen, Adv. Mater., 2014, 26(28), 4763-4782.

[2] G. A. Snook, P. Kao and A. S. Best, J. Power Sources, 2011, 196(1), 1-12. 
[3] C. Renault, K. Scida, K. N. Knust, S. E. Fosdick and R. M. Crooks, J. Electrochem. Sci. Technol., 2013, 4(4), 146-152.

[4] L. Hu, M. Pasta, F. L. Mantia, L. Cui, S. Jeong, H. D. Deshazer, J. -W. Choi, S. -M Han and Y. Cui, Nano Lett., 2010, 10(2), 708-714.

[5] F. Sharifi, S. Ghobadian, F. R. Cavalcanti and N. Hashemi, Renewable Sustainable Energy Rev., 2015, 52, 1453-1472.

[6] L. Hu, PNAS., 2009, 106(51), 21490-21494.

[7] L. Nyholm, G. Nyström, A. Mihranyan and M. Strømme, Adv. Mater., 2011, 23(33), 3751-3769.

[8] M. Latifatu, C. Y. Bon, K. -S Lee, L. Hamenu, Y. -I Kim, Y. -J Lee, Y. -M Lee and J. -M. Ko, J. Electrochem. Sci. Technol., 2018, 9(4), 330-338.

[9] Z. Weng, Y. Su, D. Wang, F. Li, J. Du and H. Cheng, Adv. Energy Mater, 2011, 1(5), 917-922.

[10] L. Peng, X. Peng, B. Liu, C. Wu, Y. Xie and G. Yu, Nano Lett., 2013, 13(5), 2151-2157.

[11] S.M.A. Shibli and R. Manu, Surf. Coat. Technol., 2005, 197(1), 103-108.

[12] C. Lin and T. Wu, Electrochemistry, 2016, 84(2), 87-91.

[13] H. -K Kim and H. -C Shin, J. Electrochem. Sci. Technol., 2018, 9(1), 78-83.

[14] S. -Y Cheon, S. -Y Park, Y. -M Rhym, D. -H Kim, Y. -S Koo and J. -H Lee, J. Electrochem. Sci. Technol., 2010, 1(2), 117-120.

[15] G. O. Mallory and J. B. Hajdu, Electroless plating fundamentals and applications, first ed., AESF, 1990.

[16] J. Li, J. Li, X. Zhou, Z. Xia, W. Gao, Y. Ma and Y. Qu, ACS Appl. Mater. Interfaces, 2016, 8(17), 10826-10834.

[17] K. Zhou, W. Zhou, L. Yang, J. Lu, S. Cheng, W. Mai, Z. Tang, L. Li and S. Chen, Adv. Funct. Mater, 2015, 25(48), 7530-7538.

[18] M. Wu, J. Bai, Y. Wang, A. Wang, X. Lin, L. Wang, Y. Shen, Z. Wang, A. Hagfeldt and T. Ma, J. Mater. Chem., 2012, 22(22), 11121-11127.

[19] Y. Lu, C. D. Gua, X. Ge, H. Zhang, S. Huang, X. Y. Zhao, X. L. Wang, J. P. Tu and S. X. Mao, Electrochim. Acta, 2013, 112, 212-220.

[20] J. Fullenwarth, A. Darwiche, A. Soares, B. Donnadieu and L. Monconduit, J. Mater. Chem., 2014, 2(7), 2050-
2059.

[21] J. Y. Xiang, X. L. Wang. J. Zhong, D. Zhang and J. P. Tu, J. Power Sources, 2011, 196(1), 379-385.

[22] J. Y. Xiang, X. L. Wang, X. H. Xia, J. Zhong and J. P. $\mathrm{Tu}$, J. Alloys Compd., 2011, 509(1), 157-160.

[23] O. -H. Kwon and H. -C. Kim, J. Korea TAPPI, 2012, 44(2), 1-7.

[24] J.-S. Kim, Y.-H. Lee, I. Lee, T.-S. Kim, M.-H. Ryou and J. W. Choi, J. Mater. Chem. A, 2014, 2(28), 1086210868.

[25] Y.-H. Lee, J.-S. Kim, J. Noh, I. Lee, H. J. Kim, S. Choi, J. Seo, S. Jeon, T.-S. Kim and J.-Y. Lee, Nano Lett., 2013, 13(11), 5753-5761.

[26] B. S. Choudhury, R. S. Sen, B. Oraon and G. Majumdar, Surf. Eng., 2009, 25(5), 410-414.

[27] H. -T Yeom, Plating and surface finishing, first ed., Munundang, 2018.

[28] L. M. Abrantes, A. Fundoa and G. Jin, J. Mater. Chem., 2001, 11(1), 200-203.

[29] B. Tang, Y. Wang, L. Wang, X. Wang, H. Liu, Y. Yu and T. Sun, Surf. Coat. Technol., 2004, 186(1-2), 153-156.

[30] D. Goldbaum, J. M. Shockley, R. R. Chromik, A. Rezaeian, S. Yue, J. Legoux and E. Irissou, J. Therm. Spray Technol., 2012, 21(2), 288-303.

[31] S. Grugeon, S. Laruelle, R. Herrera-Urbina, L. Dupont, P. Poizot, and J. M. Tarascon, J. Electrochem. Soc., 2001, 148(4), A285-A292.

[32] R. Dedryvère, S. Laruelle, S. Grugeon, P. Poizot, D. Gonbeau and J.-M. Tarascon, Chem. Mater, 2004, 16(6), 1056-1061.

[33] J. Cabana, L. Monconduit, D. Larcher and M. R. Palacín, Adv. Mater, 2010, 22, E170-E192.

[34] A. Ponrouch, P. L. Taberna, P. Simon and M. R. Palacín, Electrochim. Acta, 2012, 61, 13-18.

[35] S. Liu, J. Feng, X. Bian, J. Liu and H. Xu, RSC $A d v$, 2015, 5(75), 60870-60875.

[36] W.-S Choi, W. -Y Chang and H. -C Shin, J. Solid State Electrochem., 2014, 18(2), 427-433.

[37] D. Souza, V. Pralong, A. Jacobson and L. Nazar, Science, 2002, 296(5575), 2012-2015.

[38] J. O. Besenhard, M. Winter, J.Yang and W. Biberacher, J. Power Sources, 1995, 54(2), 228-231. 